\title{
MAKNA KATA AL-RAHMAH DAN DERIVASINYA DALAM AL-QUR'AN (SUATU TINJAUAN SEMANTIK)
}

\author{
Yusrati Windah, Munir, Kamaluddin Abunawas \\ ${ }^{1}$ Pascasarjana Universitas Islam Negeri Alauddin Makassar \\ Email:yusrati19win@gmail.com
}

\begin{abstract}
ملخص
ببحث البحث عن كلمة الرحمة في القرآن التي تحتوي على كلمة مقترنة من كلمة الرحمة .الغرض من هذه الدراسة هو . 1) :

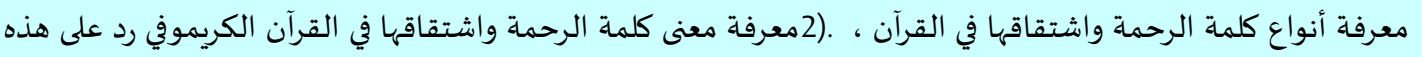

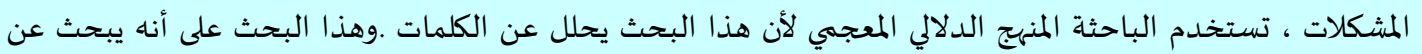

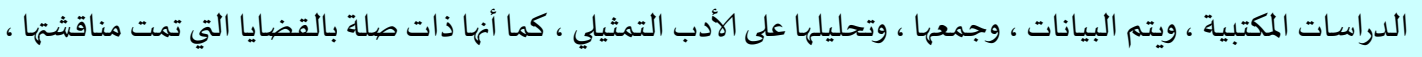

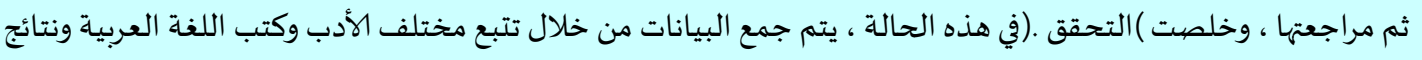

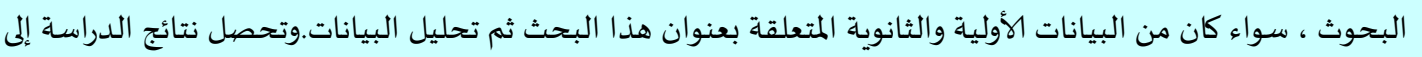

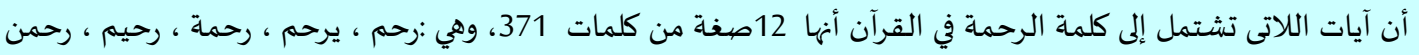

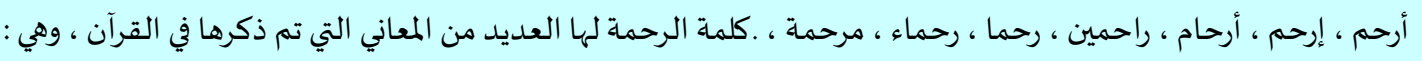

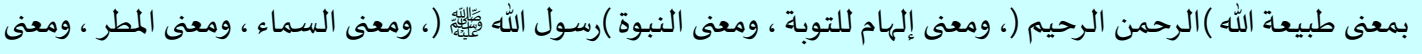

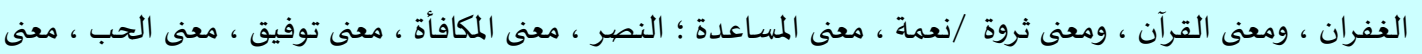

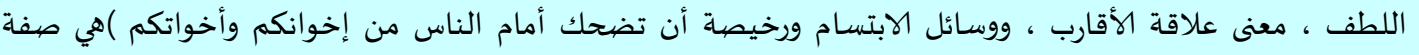
للمؤمنين(ومن المتوقع هذا البحث أن تساعد المساعدات نظرة ثاقبة إلى المعلومات ، خاصاة في مجال تعليم اللغة العربية وإثراء الملكية الفكرية للمجتمع ، خاصنة بالنسبة للمسلمين فيما يتعلق بمعنى كلمة الرحمة .واشتقاها في القرآن الكريم.

الكلمات المفتاحية: معنى، كلمة الرحمة، الاشتقاق
\end{abstract}

\section{Abstract}

This article discusses the word al-Rahmah in the Qur'an which has a derivative of words (Derivation) from the word al-Rahmah. The purpose of this study is to knowing the classification of the word al-Rahmah and its derivation in the Qur'an dan knowing the meaning of the word al-Rahmah and its derivation in the Qur'an. In answering these problems, the author uses the lexical semantic approach because this study analyzes the word. This research is classified as library research; data is collected by tracing various literature, Arabic language books and research results, both from primary and secondary data related to the title of this research and then analyzing the data. The results of the study concluded that the verses of the word al-Rahmah in the Qur'an are classified into 12 words of the number 371 words, namely: رحماء, رحما ,راحمين ,أرحام رإرحم ,أرحم رحمن ,رحيم رحمة ,يرحم ,رحم) . The word al-Rahmah has many meanings that have been mentioned in the Qur'an, namely: meaning the nature of Allah (the Most Merciful and Merciful), meaning to inspire repentance, prophethood (Rasulullah Saw), heaven, rain, forgiveness, the Qur'an, fortune/ni'mat, means help; victory, reward, taufiq, compassion, gentleness, kinship relationship, and means to smile and cheaply laugh in front of the people of your brothers and sisters in faith (is the nature of your people).

Keyword: Meaning Qur'an; Al-Rahmah; Derivation 


\section{PENDAHULUAN}

Al-Quran adalah mukjizat Islam yang kekal abadi sepanjang zaman sekaligus kitab pedoman bagi kehidupan umat manusia dalam hubungannya dengan Sang Pencipta, interaksi antar sesama manusia serta relasinya terhadap alam sekitar. Mukjizat al-Qur'an selalu diperkuat oleh kemajuan ilmu pengetahuan. Inilah salah bukti bahwa al-Qur'an kitab suci yang sangat luar biasa kemukjizatannya.

Al-Quran diturunkan kepada Nabi Muhammad s.a.w melalui Malaikat Jibril dan menjadi kitab terakhir yang membenarkan serta menyempurnakan kitab-kitab samawi yang diturunkan sebelumnya, menjelaskan segala sesuatu yang dibutuhkan bagi seorang hamba, baik itu perkara dasar dalam beragama maupun bagiannya secara terperinci. Redaksi ayatayat al-Quran turun dengan lafal berbahasa Arab, sebagaimana yang telah tertuang di dalamya, salah satunya dalam QS Yusuf/12:2.

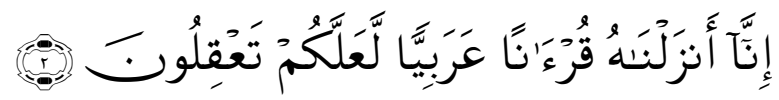

Terjemahnya:

"Sesungguhnya Kami menurunkannya berupa al-Quran dengan berbahasa Arab, agar kamu memahaminya".

Ayat ini sangat jelas menunjukkan bahwa al-Qur'an, ayat-ayatnya sarat akan makna yang dikenal kaya akan kosakata dan derivasinya. Al-Qur'an kitab Allah yang sangat Sempurna dan sangat mulia. Hal ini terbukti dengan banyaknya orang yang mempelajarinya dari segala aspek. Baik itu dari segi sejarah diturunkannya, redaksi kata-kata serta maknanya, hingga pemeliharaannya dalam upaya penghafalan dan ragam qiro'ahnya.

Dalam menyelami arti dari ayat ayat suci al-Qur'an yang sungguh sangat sarat maknanya, tidak semua orang mampu memahaminya secara keseluruhan. Hal tersebut sangat wajar karena dalam ayat-ayat al-Qur'an tidak menggunakan bahasa yang biasa melainkan bahasa yang sangat luar biasa. Intinya tiada satupun kitab di dunia ini yang lebih besar keagungannya selain al-Qur'an.

Al-Quran secara harfiah berarti "bacaan" merupakan kata bentuk masdar dari kata قَرَ yang mempunyai puncak kesempurnaan. Berarti al-Qur'an memiliki bacaan yang mahasempurna dan mahamulia. Kemahamuliaan dan kemahasempurnaan "bacaan" ini tidak hanya dapat dipahami oleh para pakar, tetapi juga oleh semua orang yang menggunakan 'sedikit' pikirannya. $^{2}$

${ }^{1}$ Kementrian Agama RI, al-Qur'an dan Terjemahnya (Aplikasi al-Qur'an Word) h. 235

${ }^{2}$ M. Quraish Shihab, Lentera Al-Quran, ( cet. I, Bandung: Mizan, 2013), h . 21 
Sebagaimana yang telah diuraikan di atas bahwa dalam al-Qur'an mencakup berbagai aspek bahasan salah satunya yakni keindahan kata-kata dan maknanya. Dari sekian banyak kata dalam al-Qur'an yang sarat akan maknanya adalah kata alRahmah. Al-Rahmah, kata yang sering muncul pada pembicaraan kita dalam kehidupan sehari-hari dan telah menjadi rahasia umum bahwa manusia kerapkali menggunakan kata-kata walaupun sebenarnya mereka tidak mengetahui dengan baik apa yang telah dikatakannya.

Adapun beberapa contoh kata al-Rahmah yang sering digunakan, yaitu "Semoga engkau mendapat rahmat Allah", "alhamdulillah berkat rahmat Allah kita semua lulus ujian hari ini", dan bahkan kata al-Rahmah banyak yang menjadikannya nama untuk anaknya seperti rahmat untuk anak laki-laki atau rahmah untuk anak perempuan dengan harapan agar anaknya selau mendapat kasih sayang Allah (swt).

Peneliti juga telah mencari jumlah kata al-Rahmah dalam al-Qur'an dan untuk sementara, peneliti menemukan jumlah kata ar-Rahmah disebutkan sebanyak 139 kali. Kemudian Peneliti akan menelusuri kembali jumlah derivasi yang lainnya yang terdapat dalam al-Qur'an. Selanjutnya mengklasifikasikan jumlah kata, makna, dan jenis derivasinya.

Dalam memahami makna suatu kata diperlukan pengetahuan yang khusus untuk mengkaji tentang makna yakni ilmu semantik. Semantik merupakan cabang Tata Bahasa yang meliputi Fonologi, Morfologi, dan Sintaksis. Semantik diartikan sebagai ilmu bahasa yang mempelajari makna, yakni mempelajari makna yang terkandung dalam suatu lafal kata serta kolerasi yang meliputi sebuah makna itu sendiri.

Maksudnya hubungan dalam hal padanan makna, lawan makna, banyaknya makna, serta yang meliputinya baik dalam tataran fonologi, morfologi, sintaksis, dan semantik itu sendiri. Karena mengingat, makna itu pada hakikatnya bersifat secara umum dan dapat menyentuh secara keseluruhan. Penelitian ini akan menganalisis makna-makna yang terkandung dalam al-Quran terkait dengan kata al-Rahmah dan derivasinya menggunakan pendekatan semantik dan mengungkap kata-kata yang terkait dengan kata al-Rahmah. Selanjutnya menguraikan makna dibalik kata-kata.

\section{METODOLOGI PENELITIAN}

Dalam penelitian ini yang menjadi objek penelitian adalah kata-kata al-rahmah yang mengandung makna dan derivasinya dalam al-Qur'an. Adapun data-data yang dihimpun dalam hal ini sebenuhnya melalui sumber-sumber kepustakaan, maka penelitian ini merupakan penelitian pustaka (library research), yaitu penelitian yang dilakukan untuk menganalisis masalah yang bersumber dari data pustaka atau dokumen-dokumen. Langkah 
awal untuk mengkaji objek penelitian ini yaitu mengklasifikasikan bentuk-bentuk kata alRahmah karena objek penelitian ini mengenai bentuk-bentuk dan derivasi pada kata alRahmah dalam al-Qur'an. Adapun metode pendekatan yang dipergunakan dalam penelitian ini adalah pendekatan semantik. Pendekatan semantik adalah pendekatan melalui kajian tentang makna.

Jenis semantik khusus digunakan pada penelitian ini yaitu semantik leksikal karena dalam penelitian ini mengkaji perubahan-perubahan kata yang sesuai dengan bentuk dan derivasi. Adapun yang menjadi instrument dalam penelitian kualitatif ini adalah peneliti sendiri Penelitian ini adalah penelitian kualitatif yang bersifat kajian kepustakaan (library reseach). ${ }^{3}$ Analisis data adalah rangkaian kegiatan penelaahan, pengelompokan, sistematisasi, penafsiran, dan verifikasi data.

\section{PEMBAHASAN}

\section{Klasifikasi kata al-Rahmah dalam al-Qur'an}

Hal yang menarik perhatian bagi peneliti dalam artikel ini yaitu tentang makna kata al-Rahmah dan derivasinya dalam al-Qur'an karena sebelumnya peneliti telah menyusun makalah pada Mata Kuliah Leksikologi yang berjudul "Makna kata alRahmah dalam al-Qur'an" dan timbul rasa penasaran yang tinggi ingin mengungkap makna al-Rahmah yang sering peneliti dengar dan ungkapkan dalam kehidupan sehari-hari. Selain itu, peneliti telah mendapatkan sedikit wawasan dari berbagai media, baik yang bersumber dari media elektronik maupun media cetak dan peneliti ingin menggali kembali ilmu pengetahuan agar dapat menambah wawasan pribadi peneliti sendiri.

Berikut ini bagan klasifikasi kata al-Rahmah dalam al-Qur'an :

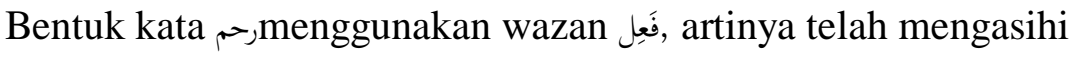

Bentuk katamenggunakan wazan يفرحسم, artinya akan/sedang mengasihi

إرحم Bentuk katamggunakan wazan artinya kasihanilah !

Bentuk kata رمة فعلة artinya kasih sayang

Bentuk kata Loرmenggunakan wazan’ُعْartinya sayang

Bentuk kata مرحمة مفعل artinya berkasih sayang

Bentuk kata رمن artinya maha pengasih

Bentuk kata رحيم فعيل فع في artinya maha penyayang

\footnotetext{
${ }^{3}$ Tujuan penelitian kepustakaan adalah untuk mengetahui lebih detail suatu masalah dari referensi yang berasal dari teori-teori baik melalui data primer maupun data sekunder. Joko Subagyo, Metode Penelitian (Cet. IV; Jakarta: Rineka Cipta, 2004), h. 109.
} 
Bentuk kata راحمينmenggunakan wazan فاعل artinya orang-orang yang mengasihi

Bentuk kata أرحم artinya sangat mengasihi

Bentuk kata أرحام أفعال artinya banyak kasih sayang

Bentuk kata رماء menggunakan wazan فعلاء artinya yang penuh kasih sayang

$$
\begin{aligned}
& \text { فعل ماض ثلاثى مجرد : رحم (سورة الانعام : 16) } \\
& \text { فعل مضارع ثلاثى مجرد : يرحم (سورة الاسرأ : } 8 \text { ) ) و ترحمون (سورة النور: 56) } \\
& \text { فعل الأمر : إرحم (سورة الإسرأ : 24) } \\
& \text { مصدر المرة : رحمة (سورة النهل : 64) } \\
& \text { ] مصدر - مصدر الأصلى : رحما (سزرة الكهف : 81) } \\
& \text { مصدر الميم : مرحمة (سزرة البلد : 17) } \\
& \text { رحمن (سورة الفاتحة : 1) } \\
& \text { اسم فاعل : راحمين (سورة يوسف : 64) } \\
& \text { اسم تفضيل : أرحم (سورة الأعراف : 151) } \\
& \text { جمع تكسير : أرحام (سورة يُمَّمَ : 22) و رحماء (سورة الهجرات : 29) }
\end{aligned}
$$

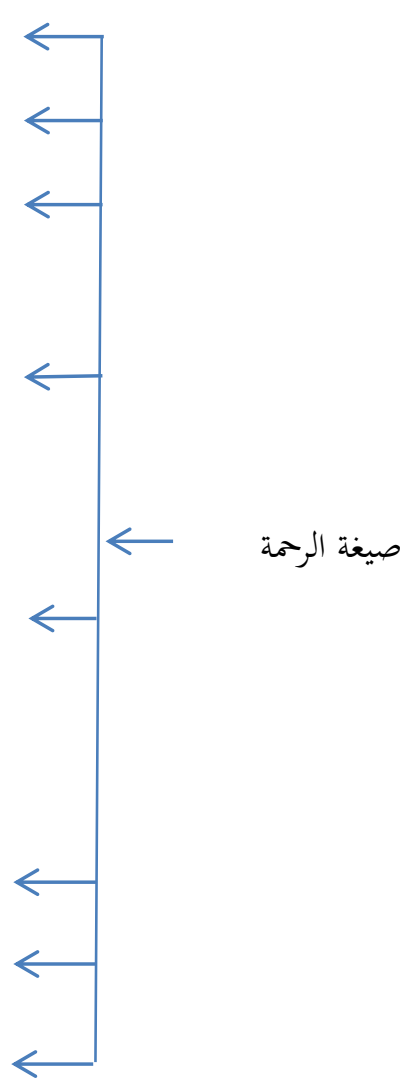

\section{Makna kata al-Rahmah dan Derivasinya dalam al-Qur'an}

Relasi makna adalah hubungan makna dari kata-kata yang berbilang makna atau hubungan makna dari sejumlah kata. Hubungan tersebut bisa berupa kesamaan, kebalikan, ketercakupan, dan sebagainya. Dalam relasi makna ini membahas hal-hal yang disebut sinonimi, antonimi, polisemi, homonimi,hiponimi, hipernimi.

Ahmad Mukhtar Umar mendefenisikan 'Ilm al-dilāah sebagai berikut:

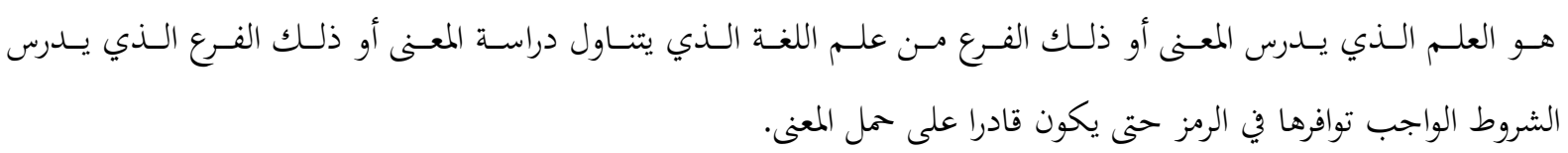

"Kajian tentang makna, atau ilmu yang membahas tentang makna, atau cabang lingusitik yang mengkaji teori makna, atau cabang lingusitik yang mengkaji syarat- 
syarat yang harus dipenuhi pada lambang-lambang bunyi sehingga mempunyai makna."4

Makna kata al-Rahmah di kelompokkan berdasarkan ilmu semantik dan leksikologi yang merupakan kajian teoritis tentang makna leksikal dalam sebuah kamus yang bahasannya meliputi: karakteristik kosakata, komponennya, perkembangan maknanya dan lain sebagainya. Karena itu, leksikologi terkadang juga digolongkan sebagai bagian dari ilmu semantik (ilm al-Dalalah) karena memang topik kajian dari kedua bidang studi tersebut hampir sama. Hanya saja, cakupan leksikologi lebih terbatas pada perwajahan kamus dan hal-hal yang berhubungan dengan isi kandungan kamus. ${ }^{5}$ Surah al-Rahmah dikaji dengan menggunakan pengelompokan sebagai berikut:

Dalam bahasa Arab, sinonim berpadanan dengan mutaradif. Syahin selain menggunakan istilah mutaradifjuga menggunakan istilah musytarak maknawi.Attawhīdi menggunakan istilah an-nazāir untuk menyebut mutarādif. Soedjito mendefinisikan sinonim sebagai dua kata atau lebih yang memiliki makna sama atau hampir sama. Misalnya, kata القمّ digunakan di Mesir, القمح-البرّ-الحنطة di banyak digunakan di Irak, dan penduduk Mekah menyebut objek yang sama dengan sebutan 2 l. $^{6}$ Secara umum, dikatakan bahwa sebab yang paling penting mengenai terjadinya sinonim dalam bahasa Arab sesuai yang telah ditetapkanoleh para ahli bahasa Arab klasik dan modern, yaitu perubahan fonem pada sebagian lafal-lafal bahasa, perubahan dilalah pada sebagian lafal, serapan dari bahasa-bahasa yang lain, perbedaan (dialek) yang terdapat pada bahasa Arab, mengenai sinonim, hal yang perlu diperhatikan yaitu tidak semua kata mempunyai sinonim. Misalnya kata beras, salju, batu dan kuning. ${ }^{7}$

Istilah antonimi berasal dari kata Yunani kuno, yaitu anti yang berarti 'melawan' dan anoma yang artinya 'nama'. Jadi antonimi secara harfiah bermakna nama-nama yang berlawanan. Secara semantik, Verhaar dalam Chaer mendefinisikan antonimi sebagai ungkapan yang maknanya dianggap kebalikan dari makna unggapan lain, misalnya kata جميل 'bagus’ berantonim dengan kata قبيح 'jelek’, يفتح 'membuka' dan يغلق 'menutup'.

\footnotetext{
${ }^{4}$ Ahmad Mukhtar Umar, 'Ilm al-dilālah (Cer. I; Kuwait: Dār al-Arūbah, 1982), h. 11.

${ }^{5}$ Hilmy Khalil, Muqaddimah lil Dirasah Al-Lughah (Iskandariyah: Al-Ma'arifah Al-Jami’iyyah), h. 333.

${ }^{6}$ Moh. Ainin dan Imam Asrori, Semantik Bahasa Arab, h. 59.

${ }^{7}$ Manqur 'Abd al-Jalil, 'Ilm al-Dilālah (Usuluhu wa Mabāḥsuhu fi al-Turà̀ al-'Arabi) (Damaskus: Mansyūrat Ittihād al-Kitab al-‘Arabī 2001), h. 37.
} 
Berbeda dengan homonimi, polisemi merupakan kata yang mempunyai makna banyak (ganda/lebih dari satu). Contoh kata رأس bermakna banyak, yaitu: bagian tubuh dari leher ke atas sebagaimana yang terdapat pada manusia dan binatang, misalnya pada satuan berikut:

'mengangkat kepala'

'memealingkan kepala'

'dari ujung kepala sampai ujung kaki'

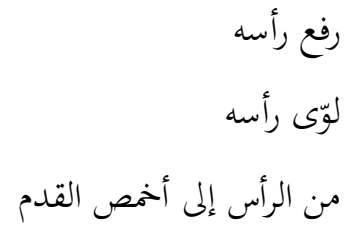

Homonimi berasal dari bahasa Yunani kuno, onoma 'nama' dan homo 'sama'. Jadi homonimi secara harfiah bermakna nama yang sama untuk sesuatu yang berbeda. Soedjito mendefenisikan homonimi sebagai dua kata atau lebih yang ejaan dan atau lafalnya sama, tetapi maknanya berbeda.

Kata hiponim berasala dari bahasa Yunani kuno, yaitu onoma berarti 'nama' dan hypo berarti 'di bawah'. Jadi secara harfiah berarti nama yang termasuk di bawah nama lain. Secara semantik menyatakan hiponim adalah ungkapan (biasanya berupa kata, tetapi kiranya dapat juga frase atau kalimat) yang maknanya dianggap merupakan bagian dari makna ungkapan lain. ${ }^{8}$ Contoh: antara kata jeruk dengan kata buah. Hal ini makna kata jeruk tercakup dalam kata buah, tetapi buah bukan hanya jeruk tapi bisa juga apel, mangga, pepaya dan jambu. Contoh dari kelompok: Antara kata melati dan kata bunga. Kata melati tercangkup dalam kata bunga, sedangkan kata bunga tidak hanya untuk melati, melainkan ada anggrek, mawar, dan lain-lain.

Hipernimi (al-Syamil) adalah kata-kata yang maknanya melingkupi makna kata-kata yang lain. Misalnya, kata binatang maknanya melingkupi makna kata-kata seperti singa, kuda, sapi, kambing, dan sebagainya. Dengan kata lain yang disebut binatang bukan hanya singa saja, tetapi termasuk juga kuda, sapi, kambing dan sebagainya. ${ }^{9}$ Ilmu Kosakata (Leksikologi). Menurut Ali al-Qasimy leksikologi atau ilmu kosakata adalah ilmu yang membahas tentang kosakata dan maknanya dalam sebuah bahasa atau beberapa bahasa. Ilmu ini memperioritaskan kajiannya dalam hal derivasi kata, struktur kata, makna kosakata, idiom-idiom, sinonim dan polisemi. $^{10}$

\footnotetext{
${ }^{8}$ Abdul Chaer, Pengantar Semantik Bahasa Indonesia, h. 98

${ }^{9}$ Abdul Chaer, Pengantar Semantik Bahasa Indonesia, h. 99.

${ }^{10}$ Ali al-Qasimy, Ilm Al-Lugah Wa Shina'ah Al-Mu'jam (Saudi Arabia: Jami'ah Malik sa'ud, 1991), h.
} 3. 
Berikut ini turunan kata (Derivasi) al-Rahmah yang terdapat dalam al-Qur'an beserta maknanya. Untuk lebih jelasnya dapat dilihat pada tabel berikut.

Tabel 4.1. Tabel bentuk kata al-Rahmah dalam al-Qur'an dan maknanya.

\begin{tabular}{|c|c|c|c|}
\hline No & Derivasi & Sighah & Makna \\
\hline 1. & (rahima) & 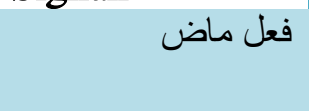 & $\begin{array}{l}\text { Memberi petunjuk ke jalan kebenaran }{ }^{11} \text {, memberi } \\
\text { kebaikan, }{ }^{12}\end{array}$ \\
\hline 2. & $\begin{array}{r}\text { رحمة } \\
\text { (rahmah) }\end{array}$ & 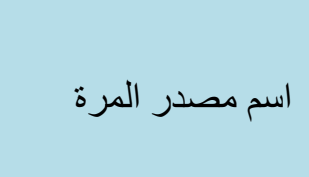 & $\begin{array}{l}\text { Kelemahlembutan, kasih sayang dan kehalusan. }{ }^{13} \\
\text { Kenikmatan, }{ }^{14} \text { kelembutan hati, }{ }^{15} \text { hujan. }{ }^{16}\end{array}$ \\
\hline 3 & مرحمة & 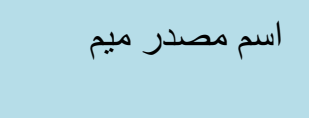 & $\begin{array}{l}\text { Saling menyayangi (berkasih sayang), } \\
\text { Kasih sayang kepada seluruh makhluk. }{ }^{17}\end{array}$ \\
\hline 4 & رحما & 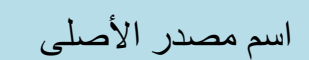 & Berbakti kepada kedua orang tua. ${ }^{18}$ \\
\hline 5 & $\begin{array}{r}\text { راحمين (rāhimīn) } \\
\text { (rion }\end{array}$ & اسم فاعل اسل & Orang-orang yang menyayangi, Para penyayang. ${ }^{19}$ \\
\hline 6 & 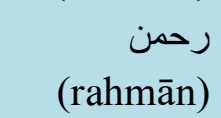 & 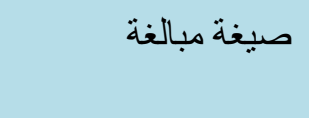 & $\begin{array}{l}\text { Maha pengasih (untuk seluruh Makhluk). Pengasih } \\
\text { di dunia. }{ }^{20}\end{array}$ \\
\hline & & & $\begin{array}{l}\text { Sifat Allah yang penuh dengan rahmat, } \\
\text { bermakna yang memberi nikmat yang lahir. }\end{array}$ \\
\hline 7 & رحيم $\begin{array}{r}\text { رحīm) } \\
\text { (rahìm }\end{array}$ & 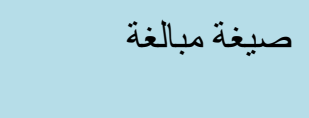 & Memberikan inspirasi untuk bertaubat ${ }^{23}$ \\
\hline 8 & (yarham) & 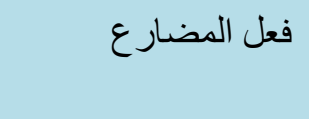 & $\begin{array}{l}\text { Merahmati/- } \\
\text { Memberi rahmat. }^{24}\end{array}$ \\
\hline & $\begin{array}{r}\text { ترحمون } \\
\text { (turhamūn) }\end{array}$ & 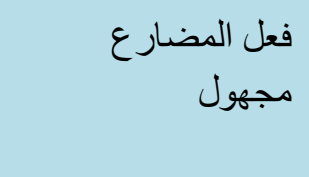 & $\begin{array}{l}\text { Orang-orang yang mendapat kasih sayang, yang } \\
\text { dikasihi, } \\
\text { diberi rahmat. }^{25}\end{array}$ \\
\hline 9 & (arham) & اسم تفضيل & $\begin{array}{l}\text { Maha penyayang. }{ }^{26} \text { Kandungan rahim/- } \\
\text { Janin. }\end{array}$ \\
\hline 10 & (arhām) & اسم جمع تكسير & hubungan kekeluargaan. ${ }^{28}$ \\
\hline 11 & (ruhamā) & 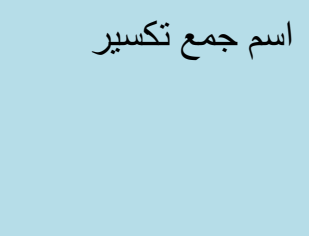 & $\begin{array}{l}\text { Kerabat-kerabat, } \\
\text { Hubungan keluarga. }{ }^{29} \text { Murah senyum dam murah } \\
\text { tertawa di hadapan orang-orang Mu'min saudara } \\
\text { seiman. }{ }^{30}\end{array}$ \\
\hline 12 & 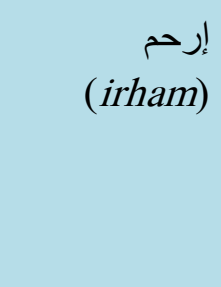 & 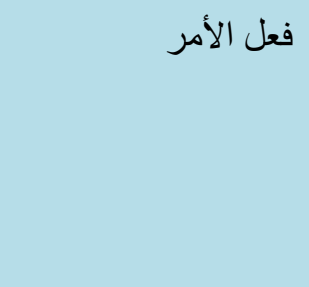 & $\begin{array}{l}\text { Kata ini merupakan kata kerja bentuk kata } \\
\text { perintah, } \\
\text { Kata kerja untuk memerintah atau mengharap } \\
\text { sesuatu. } \\
\text { Kasihanilah! }\end{array}$ \\
\hline
\end{tabular}

${ }^{11}$ Tafsir Baghawi 


\section{PENUTUP}

Berdasarkan hasil penelitian analisis makna kata al-Rahmah dan pembahasan pada uraian sebelumnya dapat disimpulkan bahwa klasifikasi kata al-Rahmah dalam al-Qur'an bentuk

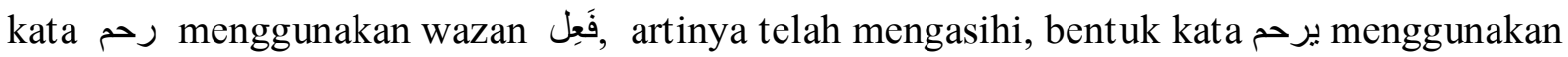

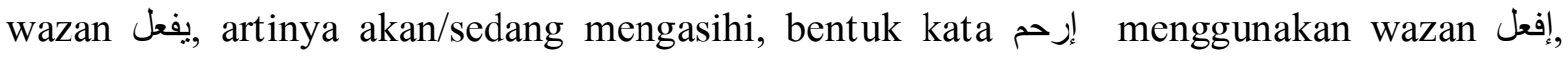

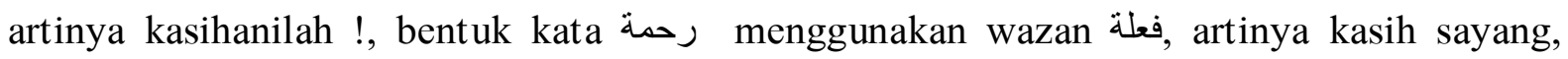

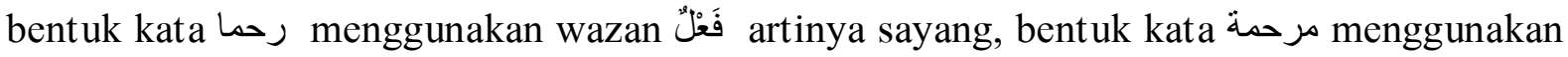
wazan مفعل artinya berkasih sayang, bentuk kata رحمن menggunakan wazan فعلان artinya

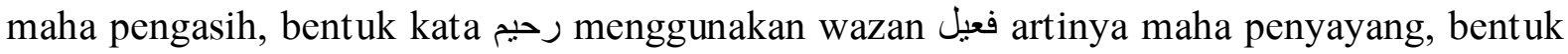
أرحم artinya orang-orang yang mengasihi, bentuk kata فاعل menggunakan wazan رحمين menggunakan wazan أرحام أفعل menggunakan

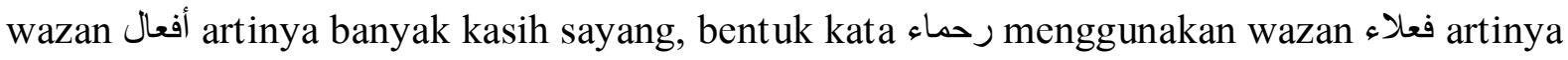
yang penuh kasih sayang.

Makna pada kata al-Rahmah dalam al-Qur'an bermakna petunjuk ke jalan kebenaran, sebagaimana yang telah dijelaskan dalam Tafsir al-Baghawi. Bermakna memberi kebaikan, hujan, kenikmatan, berbakti kepada kedua orang tua, Pemberi rahmat yang paling utama, dan kasih sayang kepada seluruh makhluk, memberikan inspirasi untuk bertaubat,

\footnotetext{
${ }^{12}$ Tafsir al-Jalalain

${ }^{13}$ Shihab M.Quraish. Menyingkap Tabir Ilahi. (Jakarta: Penerbit Lentera Hati, 2004) h.18

${ }^{14}$ Jalalain (Jalaluddin Muhammad dan Jalaluddin Abdul Rahman), Imāmain. Tafsir al-Jalālain

${ }^{15}$ Zahwa, Abu. Tafsir Surah Al-Fatihāh menurut 10 Ulama Besar Dunia (Jakarta : Penerbit Pustaka
} Azzam, 2010) h.306

${ }^{16}$ Jalalain (Jalaluddin Muhammad dan Jalaluddin Abdul Rahman), Imāmain. Tafsir al-Jalālain (Jilid 1,; Jakarta: Al-Haramain Jaya Indonesia,2007), h.392

${ }^{17}$ Tafsir Jalalain hal 809 jilid 1

${ }^{18}$ Jalalain (Jalaluddin Muhammad dan Jalaluddin Abdul Rahman), Imāmain. Tafsir al-Jalālain

${ }^{19}$ Kementrian Agama RI. Al-Qur'an Mushaf Per Kata Tajwid, Terjemah, dan Tafsir Per Kata (Jakarta; Penerbit Jabal, 2010), h. 246

${ }^{20}$ Subhani, Ja'far. Ensiklopedia Asmaul Husna (Jakarta: Penerbit Misbah, 2008). h. 165

${ }^{21}$ Razzaq, Syaikh Abdur. Ensiklopedi Asma'ul Husna (Jakarta; Pustaka Imam Syafi'i, 2017). h. 173

${ }^{22}$ Rahman, Abd. Kunci Sukses dalam al-Asma al-Husna (Makassar: Alauddin University Press, 2013). h. 64

${ }^{23}$ Jalalain (Jalaluddin Muhammad dan Jalaluddin Abdul Rahman), Imāmain. Tafsir al-Jalālain, h. 457

${ }^{24}$ Kementrian Agama RI. Al-Qur'an Mushaf Per Kata Tajwid, Terjemah, dan Tafsir Per Kata RI (Jakarta; Penerbit Jabal, 2010), h. 168

${ }^{25}$ Kementrian Agama RI. Al-Qur'an Mushaf Per Kata Tajwid, Terjemah, dan Tafsir Per Kata RI (Jakarta; Penerbit Jabal, 2010), h. 357.

${ }^{26}$ Kementrian Agama RI. Al-Qur'an Mushaf Per Kata Tajwid, Terjemah, dan Tafsir Per Kata RI (Jakarta; Penerbit Jabal, 2010), h. 169

${ }^{27}$ Sahil, Azharuddin. Indeks Al-Qur'an, (Bandung; Anggota IKAPI, 1999), h. 362

${ }^{28}$ Kementrian Agama RI. Al-Qur'an Mushaf Per Kata Tajwid, Terjemah, dan Tafsir Per Kata RI (Jakarta; Penerbit Jabal, 2010), h. 36

${ }^{29}$ Kementrian Agama RI. Al-Qur'an Mushaf Per Kata Tajwid, Terjemah, dan Tafsir Per Kata RI (Jakarta; Penerbit Jabal, 2010), h. 509

${ }^{30}$ Tafsir Ibnu Katsir, volume 7 h. 360

${ }^{31}$ https://nahwusharaf.wordpress.com 
sebagaimana yang telah dijelaskan dalam Tafsir al-Jalalain Bermakna perlindungan, sebagaimana yang telah dijelaskan dalam Tafsir ar-Razi. Bermakna sifat yang baik pada Rasulullah, merupakan sifat mu'min yaitu Murah senyum dam murah tertawa di hadapan orang-orang Mu'min saudara seiman sebagaimana yang telah dijelaskan dalam Tafsir Ibnu Katsir. Bermakna taufiq, yaitu suatu bimbingan Allah Swt yang memudahkan seseorang melakukan suatu perkara sesuai dengan hukum-Nya. Sebagaimana yang telah terdapat dalam kamus Ilmu al-Qur'an. Jadi, dapat dipahami bahwa makna kata al-Rahmah dalam alQur'an sangat luas cakupan maknanya.

\section{DAFTAR PUSTAKA}

Al-Qur'ān al-Karīm

Razzaq, Syekh Abdur. Ensiklopedi Asmaul Husna, Jakarta: Pustaka Imam Asy-Syafi'I, Penerbut Penebar Sunnah. 2016.

Jejen, Musfah. Tips Menulis Karya Ilmiah (Makalah, Penelitian, Skripsi, Tesis \& Desertasi), Jakarta: Kencana Prenadamedia Group, 2016

Kementrian Agama RI. Al-Qur'an Mushaf Per Kata Tajwid, Terjemah, dan Tafsir Per Kata RI. Jakarta; Penerbit Jabal, 2010.

Shihab, Quraish, Ensiklopedia Al-Qur'an: Kajian Kosakata, Jakarta; Lentera Hati, 2007.

Tajuddin, Shafruddin. Ilmu Dalalah (Sebuah Pengantar Kajian Semantik Arab). Matraman Jakarta Timur: Penerbit Meninjau, 2008.

Mutahar, Ali. Kamus Mutahar Arab-Indonesia, Jakarta: Penerbit Hikmah, PT Ikrar Mandiri Abadi, 2005.

Chaer, Abdul, Pengantar Semantik Bahasa Indonesia: Edisi Revisi, Jakarta: Rineka Cipta, 2002.

Tajuddin, Shafruddin. Ilmu Dalalah (Sebuah Pengantar Kajian Semantik Arab). Matraman Jakarta Timur: Penerbit Meninjau, 2008. 